\title{
Methylseleninic acid restricts tumor growth in nude mice model of metastatic breast cancer probably via inhibiting angiopoietin-2
}

\author{
Xiaojing Wu ${ }^{1 \dagger}$, Yidi Zhang ${ }^{2,4 \dagger}$, Zengyang Pei ${ }^{1}$, Si Chen ${ }^{1}$, Xu Yang ${ }^{1}$, Yin Chen ${ }^{3}$, Degui Lin ${ }^{1 *}$ and Runlin Z Ma ${ }^{2,4^{*}}$
}

\begin{abstract}
Background: Angiopoietin-2 (Ang-2) plays critical roles in vascular morphogenesis and its upregulation is frequently associated with various tumors. Previous studies showed that certain selenium compounds possess anti-tumor effects. However, the underlining mechanism has not been elucidated in detail. Plus, results of research on the anti-tumor effects of selenium compounds remain controversial.

Methods: We investigated levels of Ang-2 and vascular endothelial growth factor (VEGF) on the estrogenindependent bone metastatic mammary cancer (MDA-MB-231) cells in response to treatment by methylseleninic acid (MSeA), and further examined the effects of MSeA oral administration on xenograft mammary tumors of athymic nude mice by RT-PCR, Western, radioimmuno assay, and Immunohistochemistry.

Results: Treatment of MDA-MB-231 cells with MSeA caused significant reduction of Ang-2 mRNA transcripts and secretion of Ang-2 proteins by the cells. Level of VEGF protein was accordingly decreased following the treatment. Compared with the controls, oral administration of MSeA (3 mg/kg/day for 18 days) to the nude mice carrying MDA-MB-231 induced tumors resulted in significant reduction in xenograft tumor volume and weights, significant decrease in microvascular density, and promotion of vascular normalization by increasing pericytes coverage. As expected, level of VEGF was also decreased in MSeA treated tumors.
\end{abstract}

Conclusions: Our results point out that MSeA exerts its anti-tumor effects, at least in part, by inhibiting the Ang-2/Tie2 pathway, probably via inhibiting VEGF.

Keywords: Selenium, MSeA, Ang-2, VEGF, MDA-MB-231 cells, Xenograft tumor

\section{Background}

Selenium is an essential micronutrient element with a number of physiological functions in human. Trace amounts of Selenium are necessary for proper cellular function as components of the enzymes glutathione peroxidase and thioredoxin reductase, which indirectly reduce certain oxidized molecules in animals [1]. Selenium is also found in three deiodinase enzymes that convert one thyroid hormone to another [2]. A clear link

\footnotetext{
*Correspondence: csama@sina.com; rlma@genetics.ac.cn

${ }^{\dagger}$ Equal contributors

${ }^{1}$ The Clinical Department, College of Veterinary Medicine, China Agricultural University, Beijing 100193, China

${ }^{2}$ State Key Laboratory of Molecular and Developmental Biology, Institute of Genetics and Developmental Biology, Chinese Academy of Sciences,

Beijing 100101, China

Full list of author information is available at the end of the article
}

between selenium and thyroid function was established, and optimal intake of selenium not only aids preservation of general health but also contributes substantially to the prevention of thyroid disease [3]. Several studies suggested possible links between cancer and selenium deficiency [4-7].

Results of researches on the anti-tumor effects of selenium compounds, however, remain controversial. Some studies showed selenium induced apoptosis and cell cycle arrest of prostate cancer cells in vitro [8-12]. Selenium decreased endothelial MMP-2 and VEGF in epithelial cancer cells, inhibited the mitosis and induced G1 arrest of umbilical vein endothelial [13-16]. Recent studies showed that MSeA treatment could downregulate hypoxia-inducible factor- $1 \alpha$ in invasive prostate cancer [17]. At in vivo level, oral MSeA treatment of xenograft 
model animals inhibited the tumor growth in a dosedependent manner [15,18-20]. Evidence indicates that dietary selenium altered prostate proteomic profiles, induced a set of tumor suppressor proteins [21] and prevented chemically-induced carcinogenesis in many rodent studies [22]. An earlier randomized, placebocontrolled clinical trial showed significant beneficial effects of selenium supplementation for cancer prevention in patients with skin carcinoma [23]. On the other hand, a randomized, placebo-controlled multi-centered clinical trial (Selenium and Vitamin E Cancer Prevention Trial, SELECT) of over 35,000 men showed selenium or vitamin $\mathrm{E}$, alone or in combination at the doses and formulations used, did not prevent prostate cancer [24]. While the SELECT conclusion is convincing for the tested selenium compound of L-selenomethionine (SeMet), certain caution may be necessary in extrapolative interpretation of the results. Because ruling out the efficacy of SeMet does not necessarily ruling out the efficacy of all other bioactive Se forms [21,25]. Due to the documented differences in metabolic and biological properties between SeMet and MSeA, investigation on functions of MSeA still holds promise for potential cancer prevention.

Although previous studies showed certain selenium compounds possess anti-tumor effects, the underlining mechanism has not been fully elucidated. In particular, there is no detailed data showing exactly how MSeA is linked to inhibition of angiogenesis, a process critical for continuation of most tumor growth. Current evidences more or less linked to the inhibition of VEGF and MMP2 by MSeA, as well as to the G1 arrest of cells.

In this study, we investigated the effects of MSeA on the estrogen-independent bone metastatic mammary cancer (MDA-MB-231) cells and the tumors induced by the cells on athymic nude mice. We examined mRNA transcription and protein expression of Ang-2 at several concentration levels of MSeA on MDA-MB-231 cells, tested VEGF levels in vitro and in vivo in response to the MSeA treatments, compared the xenograft tumors for weight, volume and microvascular density following the MSeA treatment. Here we show direct evidence that MSeA at selected concentrations caused significant reduction in Ang-2 mRNA transcription and Ang-2 protein secretion in MDA-MB-231 cells. Because Ang-2/ Tie2 is known as a key regulator for tumor growth $[26,27]$, our results help to explain the mechanism of anti-tumor function by MSeA.

\section{Results}

MSeA significantly inhibited Ang-2 secretion

Compared with the PBS-controls, treatment of the MDA-MB-231 mammary cancer cell cultures with MSeA at selected non-toxic concentrations $(5 \mu \mathrm{M})$ significantly decreased $A n g-2$ mRNA transcription at the designated time intervals (Figure 1A). The inhibitory MSeA on Ang- 2 mRNA was significant $12 \mathrm{~h}$ after the treatment $(\mathrm{p}<0.05)$, and the prolonged treatment to $24 \mathrm{~h}$ did not further down regulate Ang-2 mRNA expression.

Radioimmunoassay showed that the secretion of Ang2 protein by MDA-MB-231 cells into the medium was significantly inhibited by MSeA in a concentration-

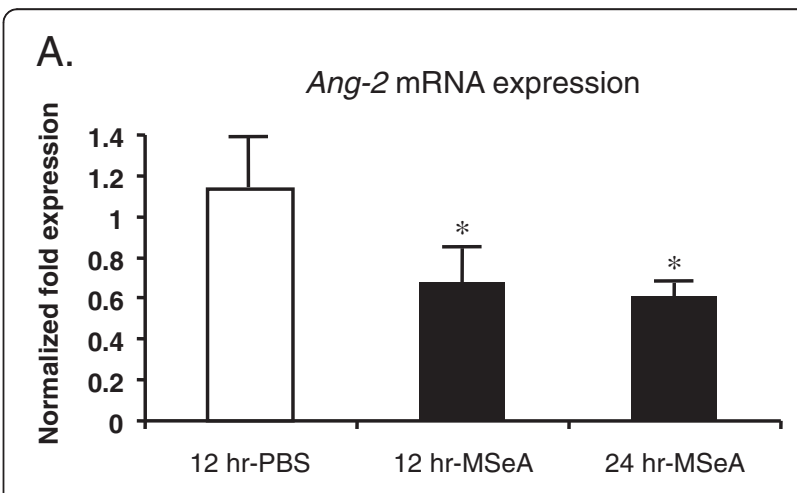

MSeA $(5 \mu \mathrm{M})$ treatment of MDA-MB-231 cells

B.

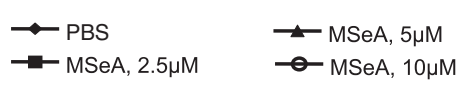
Ang-2 protein secretion

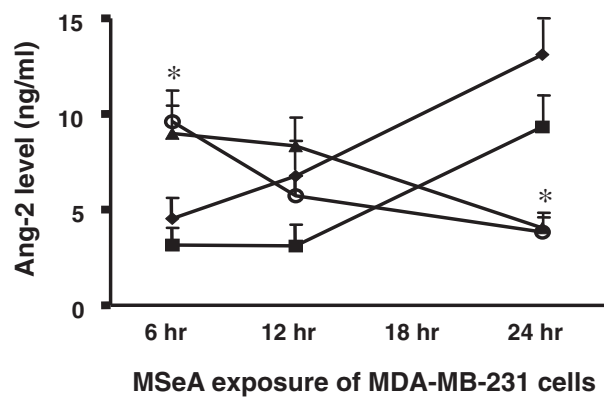

Figure 1 Inhibition of Ang-2 mRNA transcripts and Ang-2 protein secretion in cultured mammary cancer cells by the MSeA treatment. MDA-MB-231 cells were treated with selected concentrations of MSeA at the designated time intervals. Cellular mRNA and total protein from MSeA treated cells were isolated for subsequent quantitative analysis. A. Compared with the PBS controls, levels of Ang-2 mRNA in MDA-MB-231 cancer cells were significantly reduced $12 \mathrm{hrs}$ following the MSeA $(5 \mu \mathrm{M})$ treatment, determined by quantitative RT-PCR $(p<0.05)$. MSeA treatment of the cells for 24 hrs did not further inhibit Ang-2 mRNA expression. B. Secretion of Ang-2 protein into the medium by the MDA-MB-231 cells were significantly inhibited $(p<0.05) 24$ hrs following the MSeA treatment at concentrations $5 \mu \mathrm{M}$ or higher, as determined by Radioimmunoassay (RCA). Compared with the PBS control, a brief but significant increase in Ang-2 protein secretion was observed for the MDA-MB-231 cells at 6 hrs following the $5 \mu \mathrm{M}$ and $10 \mu \mathrm{M}$ MSeA treatments, and the reason is currently unknown to us. 
dependent manner (Figure 1B), consistent with that of Ang-2 mRNA transcription. The baseline secretion of Ang-2 (MSeA $=0 \mu \mathrm{M})$ showed a steady increase over time, and the treatment of MSeA at lower concentration $(2.5 \mu \mathrm{M})$ did not significantly affect the trend of secretion. In contrast, higher concentrations of MSeA $(\geq 5 \mu \mathrm{M})$ significantly reversed the levels of Ang-2 protein to the minimum $24 \mathrm{~h}$ following the treatment ( $\mathrm{p}$ $<0.05$ ). We also noticed a brief but significant increase in the level of Ang-2 protein at $6 \mathrm{hrs}$ following the $5 \mu \mathrm{M}$ and $10 \mu \mathrm{M}$ MSeA treatments (Figure 1B), and the significance of this phenomenon is currently unknown to us.

\section{MSeA decreased level of VEGF production}

Western blot experiments showed that, comparing with the indigenous level of $\beta$-Actin, exposing MDA-MB-231 cells to MSeA treatment caused distinct reduction in the cellular VEGF protein in a concentration-dependent manner (Figure 2). MSeA at a lower concentration $(2.5 \mu \mathrm{M})$ showed no significant effect on level of VEGF $12 \mathrm{~h}$ after the treatment. However, the inhibition effect was obvious at higher MSeA concentrations $(5 \mu \mathrm{M}$ and
$10 \mu \mathrm{M})$. Prolonged MSeA treatment of the cells for $24 \mathrm{hrs}$ did not further inhibit the VEGF protein production.

Immunohistochemistry analysis of the tumor VEGF showed that the xenograft tumors of athymic nude mice induced by MDA-MB-231 cells had a distinct reduction of VEGF following the MSeA treatment (Figure 3). Oral administration of MSeA to the nude mice significantly reduced the number of cells producing VEGF, as visualized by the IHC staining (Figure 3B). The averaged intensity score of cellular VEGF for the MSeA-treated tumor was 1.0 (weak staining), while as the same score for the non-MSeA treated control tumor was greater than 2.0 (dark brown cytoplasm staining).

\section{MSeA restricted the growth of xenograft tumors}

Compared with water blank controls, oral administration of MSeA to the nude mice at $3 \mathrm{mg} / \mathrm{kg} /$ day for 18 days significantly reduced the growth of xenograft tumors induced by MDA-MB-231 cells (Figure 4). Average tumor volume deceased approximately $44 \%$ in the MSeA treatment group (Figure 4A), and the mean tumor weight decreased approximately 46\% (Figure 4B). The

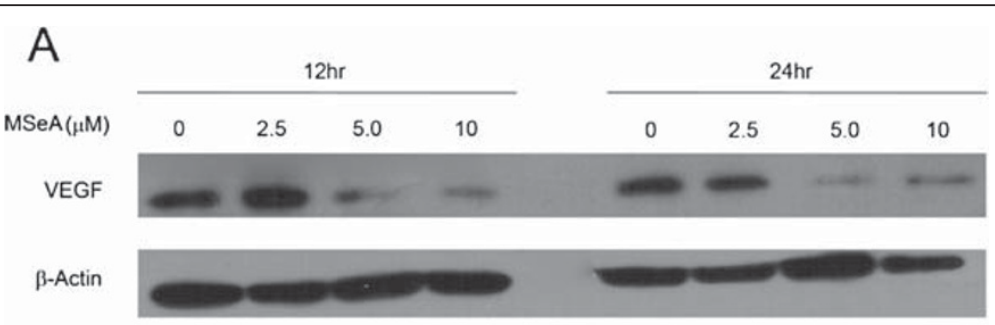

B
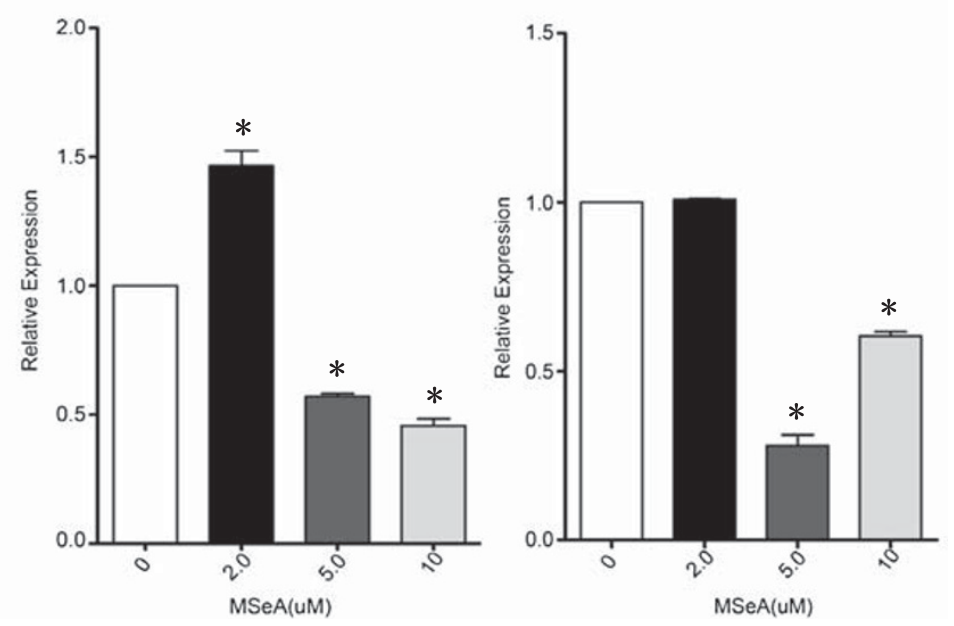

Figure 2 Western blot showing the level of vascular endothelial growth factor (VEGF) in MDA-MB-231 cells was dramatically reduced following the treatment of MSeA at $5 \mu \mathrm{M}$ for $12 \mathrm{hrs}$. A higher MSeA concentration (10 $\mu \mathrm{M})$ or longer treatment period (24 hrs) did not further inhibit the VEGF production. Commercial antihuman VEGF antibody (1: 200XD) was used to visualize the cellular VEGF protein band at the given MSeA concentrations and treatment time periods. 

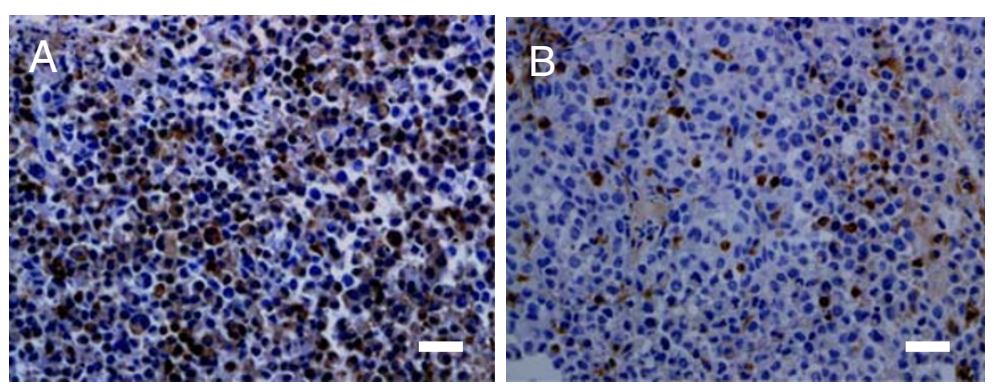

C.

Mean VEGF Positive cell

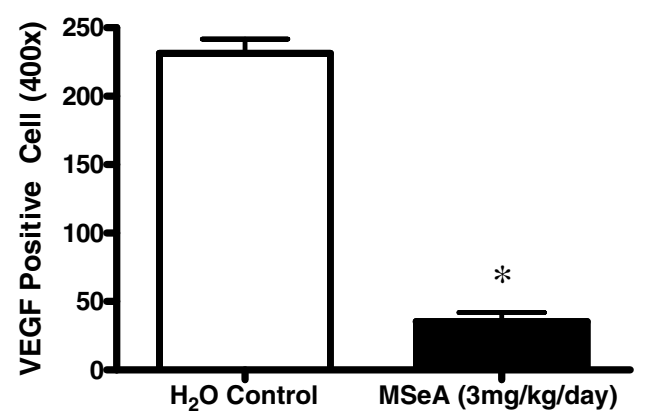

Figure 3 Immunohistochemistry (IHC) stain for VEGF showed a lower level of VEGF expression in the xenograft tumor from the animal received MSeA-treatment. A. Control. Target VEGF protein (brown cytoplasm) was extensively and highly expressed in a MDA-MB-231 cell-induced tumor of a representative nude mouse receiving no MSeA administration as control. B. MSeA treatment. VEGF protein expression was at a much lower percentage and level in xenograft tumor of a representative nude mouse receiving oral administration of MSeA at $3 \mathrm{mg} / \mathrm{kg} /$ day for 18 days. Scale bar $=50 \mu \mathrm{m}$. C. Statistical summary of VEGF positive cells for the control tumor $($ Mean $=234$ cells/field, $n=3)$ and the MSeA treatment (Mean $=45$ cells/field, $n=3)(P<0.05)$.

reduction in the tumor volume became significant at 16 days following the MSeA treatment. Meanwhile, differences in mean body weight of the nude mice was not significant between the MSeA-treatment $(\mathrm{w}=17.9 \pm 0.8 \mathrm{~g}$; $\mathrm{n}=8)$ and the control group ( $\mathrm{w}=18.7 \pm 0.7 \mathrm{~g} ; \mathrm{n}=8)$.

Immunohistochemistry (IHC) staining of the xenograft tumor sections using CD31 antibody showed that the microvessel density for the MSeA-treated tumor was significantly less (Figure 5B) when compared with that of non-MSeA controls (Figure 5A). Statistical analysis showed that the averaged microvessel density, expressed by the CD31-positive counting per 200X-view field for the MSeA-treatment and the control group, was $54 \pm 4$ and $87 \pm 19$, respectively. There was a $38 \%$ decrease in microvessel density in the treatment group $(\mathrm{p}<0.05)$.

MSeA induced microvascular maturation of the xenograft tumor. IHC double-staining using CD31 and $\alpha$ SMA antibodies showed that, while the tumors from the control group exhibited more of CD31 staining for microvessel density (Figure 6A), the tumors receiving MSeA treatment showed more of $\alpha$-SMA staining for pericytes (Figure 6B). The average percentage for $\alpha$ SMA stain of the MSeA-treated and the control groups was $80 \pm 3 \%$ and $60 \pm 3 \%$, respectively. Quantitative analysis of pericyte coverage showed about $20 \%$ increase in VMI (Vascular Maturation Index) in MSeA-treated tumors compared with the non-treated tumors (Table $6 \mathrm{C}, \mathrm{p}<0.05)$. Increased pericytes coverage is considered as a sign of microvascular maturation, which promotes vascular normalization.

Suppression of endogenous VEGF or Ang-2 mRNA expression by RNA interference (RNAi) in MDA-MB-231 cells showed that, while both of the levels of VEGF and Ang-2 dropped significantly when any one of the two was inhibited, siRNA inhibition of VEGF caused dramatic drop of Ang-2 expression (Figure 7). In contrast, siRNA inhibition of Ang-2 caused less drop of VEGF level. Our results indicate that $A n g-2$ was more likely located downstream of $V E G F$.

\section{Discussion}

Our data showed that oral administration of MSeA to the athymic nude mice could significantly restrict the growth of xenograft tumors induced by mammary cancer MDA-MB-231 cells. Compared with the corresponding controls, the anti-tumor effects of MSeA were demonstrated in the nude mice model by significant reduction of xenograft tumor volume and weight, 


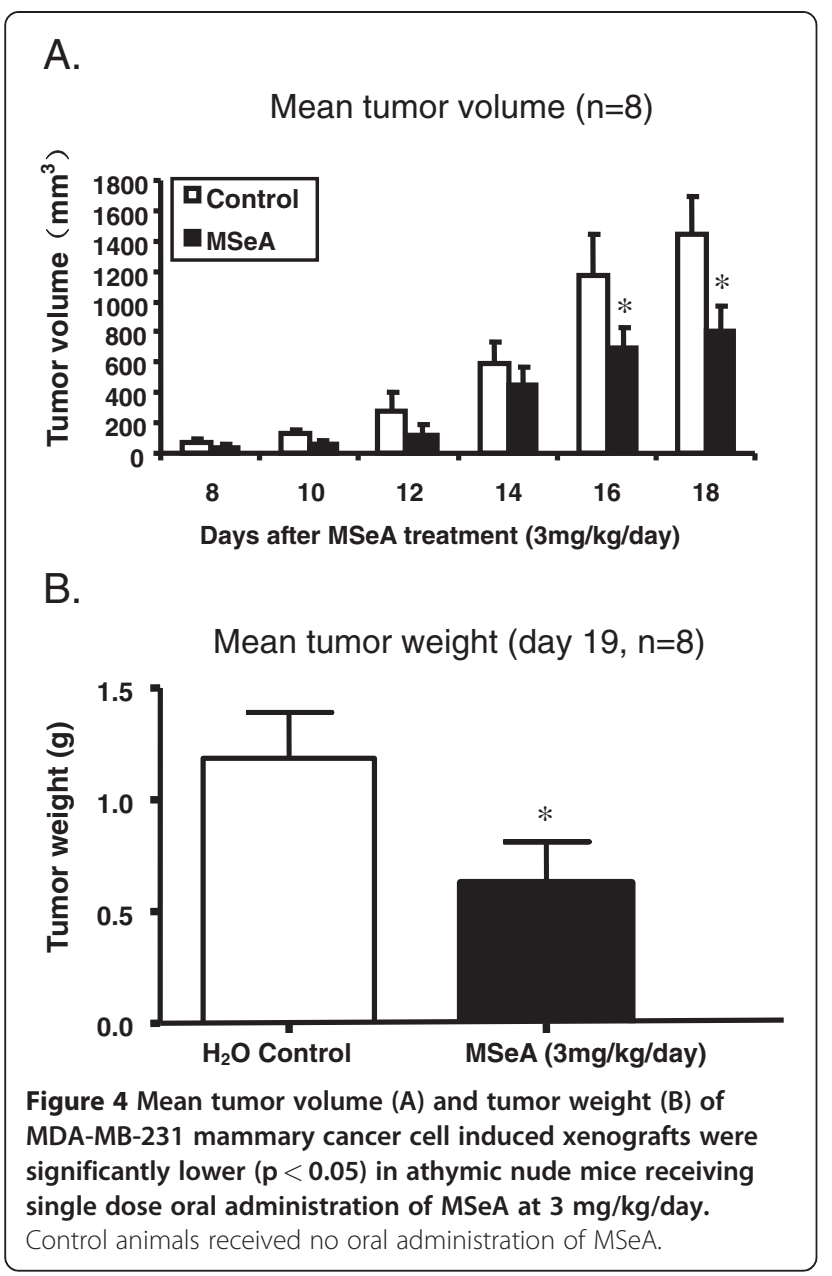

significant decrease in microvessel density of the tumors, plus promotion of vascular maturation and normalization by increasing pericytes coverage. The level of VEGF was significantly decreased in the tumors of the mice receiving the $\mathrm{MSeA}$ treatment. It is well known that VEGF plays an important role in solid tumor progression by stimulating microvessel growth, which in turn facilitates the oxygen and nutritional supply to tumors $[27,28]$. Our results are consistent with and are comparable to the anti-tumor effects of MSeA previously reported by other researchers $[11,16,18,25,29]$. The statement that proper concentrations of MSeA is potentially beneficial to human health in possessing the anti-tumor effects have the solid support of experimental evidences, at least in the xenograft animal models.

Our results indicate that partial inhibition of Ang-2 secretion may contribute, at least in part, to the mechanism of anti-tumor effects of MSeA. The levels of both cellular VEGF and Ang-2 secretion were significantly decreased following the MSeA treatment (Figures 1 \& 2 ). Our results not only confirmed the previous reports for inhibition of VEGF by MSeA [13,14], but also demonstrated that MSeA could significantly reduce Ang-2 protein secretion, at least in the mammary cancer cells. Ang-2 can be produced by both vascular endothelial cells and certain cancer cells in relatively low level [30]. The level of Ang-2 in the serum of the nude mouse carrying the xenograft tumors was not measured due to potential confounding of secretion by both the xenograft tumor cells and the microvessels of mice origin. Instead we used MDA-MB-231 cells to estimate the effect of MSeA on Ang-2 secretion. To our knowledge, this is the first time that MSeA is linked to inhibition of Ang-2, a critical components in angiogenesis pathway. Our data showed that inhibition of Ang-2 secretion was apparently via the inhibition of $A n g-2$ mRNA transcription (Figure 1A).

Both of our results and previous research showed that MSeA inhibited the VEGF, which partially explain the mechanism of action of the MSeA [13,14]. Direct evidence on whether or not MSeA works simultaneously on both VEGF and Ang-2, or it works on sequential in a signal pathway, is currently non-conclusive to us. Since some research showed that Ang-2 are likely placed at the down stream of VEGF pathway and are regulated by VEGF [31,32], it is possible that the mechanism of antitumor by MSeA is to inhibit Ang-2, probably via inhibiting VEGF. For the relationships between VEGF and Ang-2, our results of the siRNA experiments are consistent with the findings by Zhang et al. [32], which support the statement that VEGF regulates the Ang-2 in the vascular endothelial cells.

Demonstration of Ang-2 inhibition by MSeA treatment has the profound significance. Ang-2 belongs to a family of growth factors that are critically involved in blood vessel formation during developmental and pathological angiogenesis [28,33-35]. The Ang-2/Tie-2 system acts as a vascular specific ligand/receptor system to control endothelial cell survival and vascular maturation [26,36-38]. Association between MSeA and Ang-2 inhibition, therefore, provide additional evidence of MSeA as a plausible candidate for certain caner prevention and treatment.

\section{Conclusions}

Our results not only showed that MSeA significantly restricted xenograft tumor growth at the concentrations chosen, but also demonstrate that MSeA exerts its antitumor effects, at least in part, by inhibiting the Ang-2/ Tie2 pathway, probably via inhibiting VEGF.

\section{Methods}

Animals and cells

Female Balb/c athymic nude mice of 6-7 week old were purchased from the Laboratory Animal Center, Cancer Institute, Chinese Academy of Medical Sciences. The colonies were maintained under the SPF condition in 

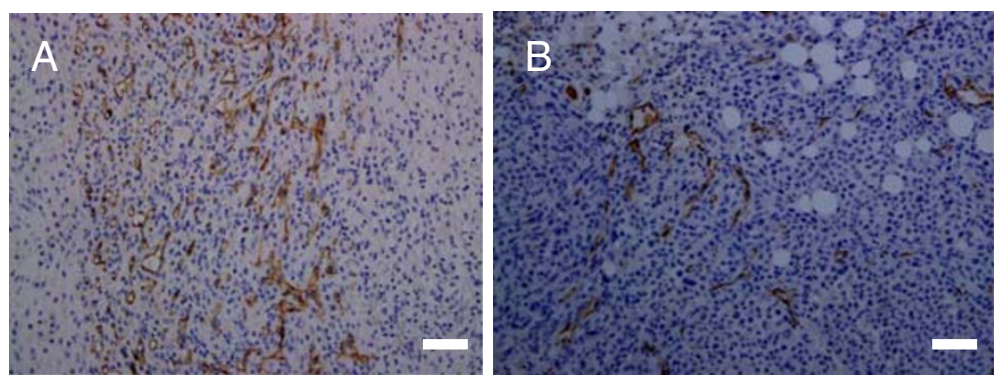

C.

Microvessel density

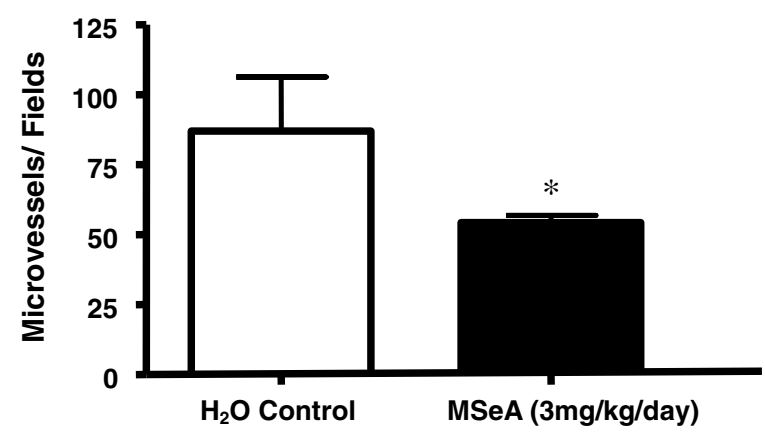

Figure $\mathbf{5}$ MSeA treatment significantly reduced the microvessel density of the xenograft tumor. A. Control. IHC staining for CD31 (brown) showed that the microvessel density was much higher in xenograft tumors from the nude mice received no oral administration of MSeA. B. MSeA treatment. Single dose oral administration of the nude mice with MSeA at $3 \mathrm{mg} / \mathrm{kg} /$ day $\times 18$ days resulted in significant reduction in microvessel density, as indicated by CD31 IHC staining. Scale bar $=100 \mu \mathrm{m}$. C. Statistical summary of the microvessel density in the treatment and the control groups. A reduction of $38 \%$ in microvessel density was observed in the MSeA-treated nude mice $(p<0.05)$, with mean density for the control and MSeA-treatment group being $87 \pm 19$ and $54 \pm 4$, respectively (student- $t$ test).

the same facilities for all of the experimental procedures. The animal usage protocols were approved in advance by both of Animal Care and Use Committees of the Chinese Academy of Medical Sciences and Chinese Agricultural University.

Cultural stock of estrogen-independent mammary cancer cells (MDA-MB-231 cells) was purchased from American Type Culture Collection (ATCC, HTB-26"). Working stock of the cell lines were maintained under standard DMEM media with $10 \%$ fetal bovine serum and $1 \%$ penicillin/streptomycin as antibiotics (Hyclone), in a $37{ }^{\circ} \mathrm{C}$ incubator with $5 \%$ high purity $\mathrm{CO}_{2}$.

\section{Chemicals and reagents}

Methylseleninic acid (MSeA) used was obtained commercially (Sigma, \#541281, $\mathrm{CH}_{3} \mathrm{SeO}_{2} \mathrm{H},>95 \%$ ). Stock solutions of MSeA at $0.5 \mathrm{mg} / \mathrm{ml}$ and $10 \mathrm{mM}$ concentration were prepared in deionized distilled water and PBS solution, respectively; the stock solutions were filtersterilized and stored in $1 \mathrm{ml}$ aliquots under $-70{ }^{\circ} \mathrm{C}$ for routine usage. Antibodies for CD31 (Santa Cruz, SC1506), $\alpha$-SMA (Abcam, ab-5694), and VEGF (Santa Cruz, SC-152) were obtained commercially and used following the instructions of the providers. All other chemicals and reagents used were at molecular biology grade.

\section{Generation of xenograft tumor model}

To investigate the effect of MSeA treatment on tumor growth, an animal model was generated by induction of xenograft tumors using MDA-MB-231 cells in athymic nude mice. MDA-MB-231 cells $\left(\sim 3 \times 10^{6}\right.$ per animal) were subcutaneously inoculated into the right flank of each mouse and the animals were then randomly divided into two groups for comparison. One group received single-dose oral gavage administration of MSeA (3 mg/ $\mathrm{kg} \mathrm{BW/animal)} \mathrm{per} \mathrm{day} \mathrm{for} 18$ days (MSeA-treatment) and the other group received $\mathrm{H}_{2} \mathrm{O}$ as control. The induced tumors in both groups were measured by vernier calipers for volume (length $\times$ width $^{2} \times 0.5$ ) at the designated time intervals. At the $19^{\text {th }}$ day, all the tumors were harvested for subsequent analysis on tumor weights, microvessel densities, and vascular maturation.

Microvessel density of the xenograft tumors was determined by immunohistochemistry (IHC) staining of the tumor sections using CD31 antibody specific for endothelial cells of microvessels [39,40]. For both MSeAtreatment and control group, microvessel density index was determined by counting CD31-marked endothelial cell clusters on three chosen fields of the highest density blood vessels at (200X) magnifying power. Quantifications were independently performed by two investigators 

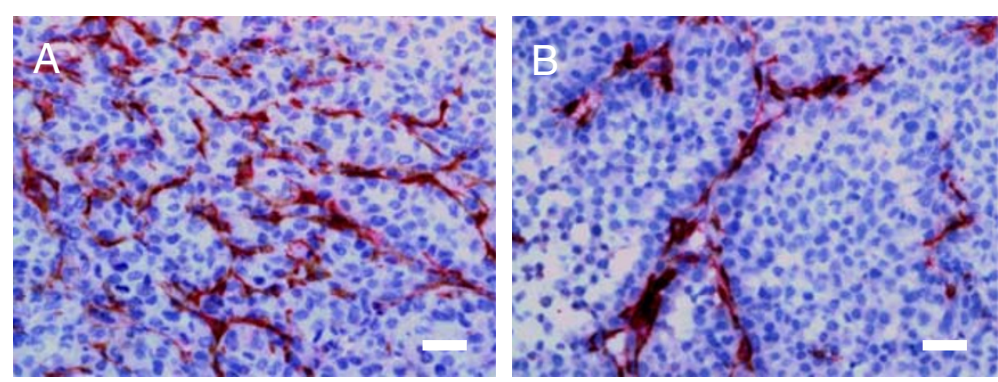

C.

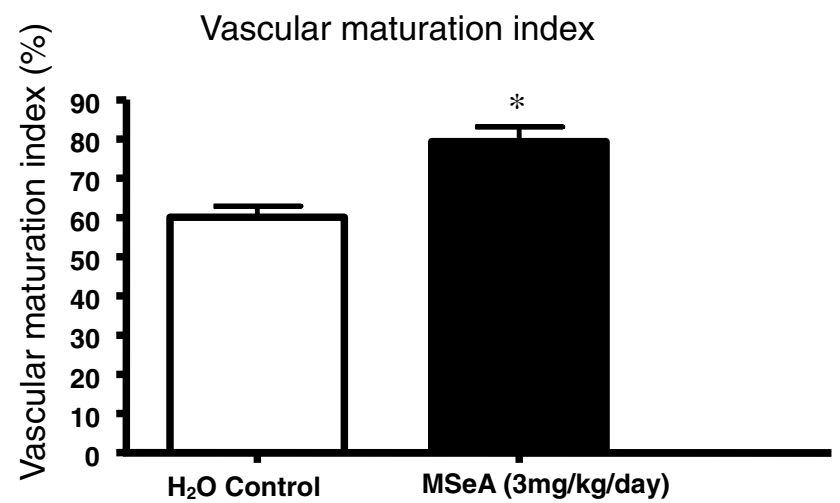

Figure $6 \mathrm{MSeA}$ facilitates vascular normalization by induction of vascular maturation. A. Control. IHC double-staining for both of CD31and a-SMA showed that, the xenograft tumor from the nude mice with no MSeA treatment developed dense microvessels (red) but less surrounding pericytes (brown), indicating less maturation of the microvessels; B. MSeA treatment. The IHC double-staining showed increased presentation of a-SMA marker for pericytes (dark brown) along with the blood vessels of the tumor from the nude mice received oral administration of MSeA at $3 \mathrm{mg} / \mathrm{kg} /$ day for 18 days. Scale bar $=50 \mu \mathrm{m}$. C. Statistical summary of vascular density index. The Vascular Maturation Index (VMI) for the control group and the MSeA treatment group was $60 \pm 3 \%$ and $80 \pm 3 \%$, respectively $(p<0.05)$.

for statistical analysis. VEGF antibody was used to visualize levels of VEGF in the xenograft tumors for treatment and control groups.

Effect of MSeA on vascular maturation of the xenografts was determined by IHC double staining of the tumor sections with both CD31 and $\alpha$-SMA antibodies $[18,41]$. For the MSeA-treatment and the control group, visual counting of double-stained $\alpha$-SMA/CD31 areas vs. the positive CD31-only tissue areas was performed. Each tumor section was examined for ten random fields under 400X magnification for statistical analysis. The blood vessels of the MSeA treatment groups and the control group were analyzed independently by two investigators.

\section{Real-time PCR and Western blot}

To assess whether MSeA could affect the transcriptional levels of key genes/mRNAs potentially associated with tumor development in MDA-MB-231 cells, total cellular RNA from the MSeA-treated and the PBS control cells were isolated using Trizol reagent (Invitrogen) [42]. For the treatment, MSeA at a concentration of $5 \mu \mathrm{M}$ as added into the DMEM medium when cells reached 60-70\% confluence. Control cells received PBS treatment. Total RNAs were isolated at $12 \mathrm{~h}$ and $24 \mathrm{~h}$ after the treatment and $2 \mathrm{mg}$ of total RNA from each group was subjected for the $1^{\text {st }}$ strand cDNA synthesis by reverse transcription. Quantitative PCRs were performed with the SYBR Premix TaqReal-Time PCR Detection System (TaKaRa) on a real-time thermal cycler (Bio-Rad Laboratories, Inc., USA). Each qPCR reaction was run in triplicates and relative amount of mRNA for each gene was normalized based on house keeping gene $\beta$-Actin. The forward and reverse primer sequence for $A n g-2$ mRNA amplification was 5AGATTTTGGACCAGACCAGTGA-3' and 5'-GGAT GATGTGCTTGTCTTCCAT-3' respectively [22]. Total cellular proteins were isolated from both MSeAtreated and PBS-treated cells for Western analysis, and VEGF antibody was used to visualize level of cellular VEGF after electrophoresis.

\section{Radioimmuno assay}

To examine whether the MSeA treatment could affect secretion of Ang-2 by MDA-MB-231 cells, radioimmuno assay was utilized to measure the level of Ang-2 in cell medium using a commercial Ang-2 RIA KIT (Sinoukbio, HY174). Instructions from the kit provider were followed in the entire experimental procedures and the 


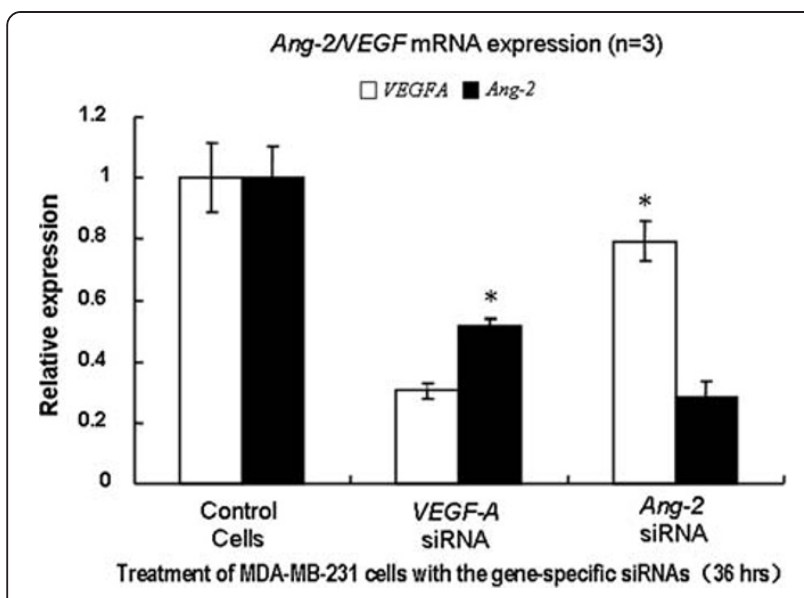

Figure 7 RNA interference of VEGF and Ang-2. MDA-MB-231 cells were transfected with the pooled siRNAs with lipofectamine 2000 (Invitrogen). Thirty-six hours after the transfection, total RNA from cultured cells was extracted by use of Trizol (Invitrogen). Real-time quantitative PCR was conducted to assess the level of the target mRNA expression using SYBR green dye, with relative changes calculated by the $\Delta \Delta \mathrm{Ct}$ method. While the suppression of either of VEGF or Ang-2 caused significant reduction of the other when compared with the siRNA controls, inhibition of VEGF lead to a dramatic decrease in the level of Ang-2. The results indicate that Ang-2 is more likely regulated by VEGF.

data analysis. Detection principle is essentially the same as to that described previously [43]. Briefly, following the treatment of cells with MSeA at $0 \mu \mathrm{M}$ (no treatment), $2.5 \mu \mathrm{M}, 5.0 \mu \mathrm{M}$ and $10 \mu \mathrm{M}$ concentrations after $6 \mathrm{~h}, 12 \mathrm{~h}$, and $24 \mathrm{~h}$ period of time, $50 \mu \mathrm{l}$ of cell culture supernatant from each treatment was collected to measure the level of radioactivity-labeled ${ }^{125}$ I-Ang-2 in the medium on an R-911 full-automatic radioimmuno calculating instrument. Measurement for each treatment was conducted in triplicates.

\section{RNA interference of VEGF and ang-2}

To assess the regulation relationships between VEGF and Ang-2 in MDA-MB-231 cells, RNA interference was utilized to suppress the target gene expression, and mRNA levels after the RNA interference were measured by the real-time quantitative PCR. Three sequence-specific siRNAs were designed for each of the target genes to ensure the effective suppression (Additional file 1: Table S1). MDA-MB-231 cells were transfected with the pooled siRNAs with lipofectamine 2000 (Invitrogen). Thirty-six hours after transfection, total RNA from cultured cells was extracted by use of Trizol (Invitrogen). Real-time quantitative PCR was conducted using SYBR green dye, with relative changes calculated by the $\Delta \Delta \mathrm{Ct}$ method.

\section{Statistical analysis}

All the numerical data collected in the experiments were statistically analyzed by ANOVA or the student $t$-test between the treatments and the controls when applicable. The data were considered significant at $\mathrm{p}<0.05$.

\section{Additional file}

Additional file 1: Table S1. CDNA sequences of VEGF and Ang-2 siRNAs.

\section{Competing interests}

Authors declare no financial or non-financial competing interests.

\section{Acknowledgements}

We thank Tao Zhu for assistance in MDA-MB-231 cells, Guangbiao Zhou and Yongqiang Liu for some of the equipments and technical assistance, Yong Tang for assistance in Radioimmuno assay, and Zheng Wang for assistance in nude mice model. This work was supported by research grants from the National Natural Science Foundation of China (30972231, 30971566), and Chinese Academy of Sciences (KSCX2-EW-R-05).

\section{Author details}

${ }^{1}$ The Clinical Department, College of Veterinary Medicine, China Agricultural University, Beijing 100193, China. ${ }^{2}$ State Key Laboratory of Molecular and Developmental Biology, Institute of Genetics and Developmental Biology, Chinese Academy of Sciences, Beijing 100101, China. ${ }^{3}$ Department of Pathology, Beijing Sanbo Brain Hospital, Beijing 100093, China. ${ }^{4}$ The Graduate University of the Chinese Academy of Sciences, Beijing 100149, China.

\section{Authors' contributions}

$X W$ and $Y Z$ carried out the molecular genetic studies, collected the data, and helped to draft the manuscript. ZP participated in the study design and performed the statistical analysis. SC participated in the data collection and helped to draft the manuscript. XY carried out some of the cell cultures. YC carried out the immunoassays. DL and RM designed the experiments, supervised the study, and wrote the manuscript. All authors read and approved the final manuscript.

Received: 19 January 2012 Accepted: 28 May 2012 Published: 28 May 2012

\section{References}

1. Almondes KG, Leal GV, Cozzolino SM, Philippi ST, Rondo PH: The role of selenoproteins in cancer. Rev Assoc Med Bras 2010, 56(4):484-488.

2. Kohrle J, Gartner R: Selenium and thyroid. Best Pract Res Clin Endocrinol Metabol 2009, 23(6):815-827.

3. Duntas LH: Selenium and the thyroid: a close-knit connection. J Clin Endocrinol Metab 2010, 95(12):5180-5188.

4. Burguera JL, Burguera M, Gallignani M, Alarcon OM, Burguera JA: Blood serum selenium in the province of Merida, Venezuela, related to sex, cancer incidence and soil selenium content. J Trace Elem Electrol Health Dis 1990, 4(2):73-77.

5. Knekt P, Marniemi J, Teppo L, Heliovaara M, Aromaa A: Is low selenium status a risk factor for lung cancer? Am J Epidemiol 1998, 148(10):975-982.

6. Russo MW, Murray SC, Wurzelmann JI, Woosley JT, Sandler RS: Plasma selenium levels and the risk of colorectal adenomas. Nutr Canc 1997, 28(2):125-129.

7. Young KJ, Lee PN: Intervention studies on cancer. Eur J Canc Prev 1999, 8(2):91-103.

8. Hu H, Jiang C, Li G, Lu J: PKB/AKT and ERK regulation of caspasemediated apoptosis by methylseleninic acid in LNCaP prostate cancer cells. Carcinogenesis 2005, 26(8):1374-1381.

9. Jiang C, Wang Z, Ganther H, Lu J: Caspases as key executors of methyl selenium-induced apoptosis (anoikis) of DU-145 prostate cancer cells. Cancer Res 2001, 61(7):3062-3070.

10. Jiang C, Wang Z, Ganther H, Lu J: Distinct effects of methylseleninic acid versus selenite on apoptosis, cell cycle, and protein kinase pathways in DU145 human prostate cancer cells. Mol Cancer Ther 2002, 1(12):1059-1066.

11. Reagan-Shaw S, Nihal M, Ahsan $H$, Mukhtar H, Ahmad N: Combination of vitamin $\mathrm{E}$ and selenium causes an induction of apoptosis of human prostate cancer cells by enhancing $\mathrm{Bax} / \mathrm{Bcl}-2$ ratio. Prostate 2008, 68(15):1624-1634. 
12. Wang Z, Jiang C, Lu J: Induction of caspase-mediated apoptosis and cellcycle G1 arrest by selenium metabolite methylselenol. Mol Carcinog 2002, 34(3):113-120

13. Jiang C, Ganther H, Lu J: Monomethyl selenium-specific inhibition of MMP-2 and VEGF expression: implications for angiogenic switch regulation. Mol Carcinog 2000, 29(4):236-250.

14. Jiang C, Jiang W, Ip C, Ganther H, Lu J: Selenium-induced inhibition of angiogenesis in mammary cancer at chemopreventive levels of intake. Mol Carcinog 1999, 26(4):213-225

15. Wang Z, Hu H, Li G, Lee HJ, Jiang C, Kim SH, Lu J: Methylseleninic acid inhibits microvascular endothelial G1 cell cycle progression and decreases tumor microvessel density. Int J Cancer 2008, 122(1):15-24

16. Wang Z, Jiang C, Ganther H, Lu J: Antimitogenic and proapoptotic activities of methylseleninic acid in vascular endothelial cells and associated effects on PI3K-AKT, ERK, JNK and p38 MAPK signaling. Cancer Res 2001, 61(19):7171-7178.

17. Sinha I, Null K, Wolter W, Suckow MA, King T, Pinto JT, Sinha R: Methylseleninic acid downregulates hypoxia-inducible factor-1alpha in invasive prostate cancer. Int J Cancer 2011, 130(6):1430-1439.

18. Bhattacharya A: Methylselenocysteine: a promising antiangiogenic agent for overcoming drug delivery barriers in solid malignancies for therapeutic synergy with anticancer drugs. Expet Opin Drug Deliv 2011, 8(6):749-763.

19. Bhattacharya A, Seshadri M, Oven SD, Toth K, Vaughan MM, Rustum YM: Tumor vascular maturation and improved drug delivery induced by methylselenocysteine leads to therapeutic synergy with anticancer drugs. Clin Cancer Res 2008, 14(12):3926-3932.

20. Bhattacharya A, Toth K, Sen A, Seshadri M, Cao S, Durrani FA, Faber E, Repasky EA, Rustum YM: Inhibition of colon cancer growth by methylselenocysteine-induced angiogenic chemomodulation is influenced by histologic characteristics of the tumor. Clin Colorectal Cancer 2009, 8(3):155-162.

21. Zhang J, Wang L, Li G, Anderson LB, Xu Y, Witthuhn B, Lu J: Mouse prostate proteomes are differentially altered by supranutritional intake of four selenium compounds. Nutr Canc 2011, 63(5):778-789.

22. Chemoprevention Database. In. www.inra.fr/reseau-nacre/sci-memb/ corpet/indexan.html.

23. Clark LC, Combs GF Jr, Turnbull BW, Slate EH, Chalker DK, Chow J, Davis LS, Glover RA, Graham GF, Gross EG, et al: Effects of selenium supplementation for cancer prevention in patients with carcinoma of the skin. A randomized controlled trial. Nutritional Prevention of Cancer Study Group. JAMA 1996, 276(24):1957-1963.

24. Lippman SM, Klein EA, Goodman PJ, Lucia MS, Thompson IM, Ford LG, Parnes HL, Minasian LM, Gaziano JM, Hartline JA, et al: Effect of selenium and vitamin $\mathrm{E}$ on risk of prostate cancer and other cancers: the Selenium and Vitamin E Cancer Prevention Trial (SELECT). JAMA 2009, 301(1):39-51.

25. Wang L, Bonorden MJ, Li GX, Lee HJ, Hu H, Zhang Y, Liao JD, Cleary MP, Lu $\mathrm{J}$ : Methyl-selenium compounds inhibit prostate carcinogenesis in the transgenic adenocarcinoma of mouse prostate model with survival benefit. Canc Prev Res Phila 2009, 2(5):484-495.

26. Mazzieri R, Pucci F, Moi D, Zonari E, Ranghetti A, Berti A, Politi LS, Gentner B, Brown JL, Naldini L, et al: Targeting the ANG2/TIE2 axis inhibits tumor growth and metastasis by impairing angiogenesis and disabling rebounds of proangiogenic myeloid cells. Canc Cell 2011, 19(4):512-526.

27. Roskoski R Jr: Vascular endothelial growth factor (VEGF) signaling in tumor progression. Crit Rev Oncol Hematol 2007, 62(3):179-213.

28. Saharinen $P$, Eklund L, Pulkki K, Bono P, Alitalo K: VEGF and angiopoietin signaling in tumor angiogenesis and metastasis. Trends Mol Med 2011, 17(7):347-362

29. Cao S, Durrani FA, Rustum YM: Selective modulation of the therapeutic efficacy of anticancer drugs by selenium containing compounds against human tumor xenografts. Clin Cancer Res 2004, 10(7):2561-2569.

30. Koga K, Todaka T, Morioka M, Hamada J, Kai Y, Yano S, Okamura A, Takakura $\mathrm{N}$, Suda T, Ushio Y: Expression of angiopoietin-2 in human glioma cells and its role for angiogenesis. Cancer Res 2001, 61(16):6248-6254.

31. Hashizume H, Falcon BL, Kuroda T, Baluk P, Coxon A, Yu D, Bready JV, Oliner JD, McDonald DM: Complementary actions of inhibitors of angiopoietin-2 and VEGF on tumor angiogenesis and growth. Cancer Res 2010, 70(6):2213-2223.

32. Zhang L, Yang N, Park JW, Katsaros D, Fracchioli S, Cao G, O'Brien-Jenkins A, Randall TC, Rubin SC, Coukos G: Tumor-derived vascular endothelial growth factor up-regulates angiopoietin- 2 in host endothelium and destabilizes host vasculature, supporting angiogenesis in ovarian cancer. Cancer Res 2003, 63(12):3403-3412.

33. Loughna S, Sato TN: Angiopoietin and Tie signaling pathways in vascular development. Matrix Biol 2001, 20(5-6):319-325.

34. Thomas M, Augustin HG: The role of the Angiopoietins in vascular morphogenesis. Angiogenesis 2009, 12(2):125-137.

35. Zadeh G, Koushan K, Baoping Q, Shannon P, Guha A: Role of angiopoietin-2 in regulating growth and vascularity of astrocytomas. J Oncol 2010, 2010:659231.

36. Brown JL, Cao ZA, Pinzon-Ortiz M, Kendrew J, Reimer C, Wen S, Zhou JQ, Tabrizi M, Emery S, McDermott B, et al: A human monoclonal anti-ANG2 antibody leads to broad antitumor activity in combination with VEGF inhibitors and chemotherapy agents in preclinical models. Mol Cancer Ther 2010, 9(1):145-156.

37. Falcon BL, Hashizume H, Koumoutsakos P, Chou J, Bready JV, Coxon A Oliner JD, McDonald DM: Contrasting actions of selective inhibitors of angiopoietin-1 and angiopoietin-2 on the normalization of tumor blood vessels. Am J Pathol 2009, 175(5):2159-2170.

38. Feng Y, vom Hagen F, Pfister F, Djokic S, Hoffmann S, Back W, Wagner P, Lin J, Deutsch U, Hammes HP: Impaired pericyte recruitment and abnormal retinal angiogenesis as a result of angiopoietin-2 overexpression. Thromb Haemost 2007, 97(1):99-108.

39. Bos R, van Diest PJ, de Jong JS, van der Groep P, van der Valk P, van der Wall E: Hypoxia-inducible factor-1alpha is associated with angiogenesis, and expression of bFGF, PDGF-BB, and EGFR in invasive breast cancer. Histopathology 2005, 46(1):31-36.

40. Vermeulen PB, Gasparini G, Fox SB, Colpaert C, Marson LP, Gion M, Belien $J A$, de Waal RM, Van Marck E, Magnani $E$, et al: Second international consensus on the methodology and criteria of evaluation of angiogenesis quantification in solid human tumours. Eur J Cancer 2002, 38(12):1564-1579.

41. Eberhard A, Kahlert S, Goede V, Hemmerlein B, Plate KH, Augustin HG: Heterogeneity of angiogenesis and blood vessel maturation in human tumors: implications for antiangiogenic tumor therapies. Cancer Res 2000, 60(5):1388-1393.

42. Simms D, Cizidziel PE, Chomczynski P: TRIZOL ${ }^{\mathrm{Tm}}$ : A new reagent for optimal single-step isolation of RNA. Focus 1994, 15(4):99-102.

43. Acebedo G, Hayek A, Klegerman M, Crolla L, Bermes E, Brooks M: A rapid ultramicro radioimmunoassay for human thyrotropin. Biochem Biophys Res Commun 1975, 65(2):449-456.

doi:10.1186/1471-2407-12-192

Cite this article as: Wu et al:: Methylseleninic acid restricts tumor growth in nude mice model of metastatic breast cancer probably via inhibiting angiopoietin-2. BMC Cancer 2012 12:192.

\section{Submit your next manuscript to BioMed Central and take full advantage of:}

- Convenient online submission

- Thorough peer review

- No space constraints or color figure charges

- Immediate publication on acceptance

- Inclusion in PubMed, CAS, Scopus and Google Scholar

- Research which is freely available for redistribution 